\title{
Assessment of Mesial Root Morphology and Frequency of MB2 Canals in Maxillary Molars using Cone Beam Computed Tomography
}

\author{
Determinación de la Morfología de la Raíz Mesial y la Frecuencia del Canal \\ MB2 en Molares Maxilares usando Tomografía Computadorizada de Haz Cónico
}

\author{
J. Abarca ${ }^{*, * *}$; B. Gómez ${ }^{* * * *}$; C. Zaror ${ }^{* * * *, * * * * *}$; H. Monardes ${ }^{* * * * * *}$; L. Bustos ${ }^{* * * * * * *}$ \& M. Cantin ${ }^{* * * *, * * * * * * * *}$
}

\begin{abstract}
ABARCA, J.; GÓMEZ, B.; ZAROR C.; MONARDES, H.; BUSTOS, L. \& CANTIN, M. Assessment of mesial root morphology and frequency of mb2 canals in maxillary molars using cone beam computed tomography. Int. J. Morphol., 33(4):1333-1337, 2015.

SUMMARY: The aim of this study was to assess the morphology of the mesial root canal system of maxillary molars and the frequency of MB2 canals using cone-beam computed tomography (CBCT). A total of 1374 teeth, first maxillary $(1 \mathrm{MS}, \mathrm{n}=802)$ and second maxillary molars ( $2 \mathrm{SM}, \mathrm{n}=572)$ of 508 Chilean patients between 8 to 77 years were evaluated through CBCT. The mesiobuccal root was evaluated in all three thirds. Root canal morphology was classified according to Vertucci's method. Data were analyzed by Pearson's Chi-square and Cuzick trend tests. MB2 canal frequency in 1MS was $73.44 \%$ and in 2MS 42.48\%. The most frequent morphology in 1MS and 2MS were Vertucci type II and I, respectively. No statistically significant association was found between frequencies and side or according to gender $(\mathrm{P}>0.05)$. A positive association was found as the age increased in both $1 \mathrm{MS}$ and $2 \mathrm{MS}(\mathrm{P}<0.001$ and $\mathrm{P}=0.023$, respectively). Given the anatomical complexity of the mesiobuccal root and the frequent presence of the MB2 canal, the clinician must assume the existence of two canals in this root. CBCT scanning is a good way to initially identify this canal in the different root thirds.
\end{abstract}

KEY WORDS: CBCT; Secondary mesiobuccal canal; MB2; Maxillary molars; Root canal system.

\section{INTRODUCTION}

One of the main purposes of endodontic treatment is to clean and disinfect root canal systems in order to reduce the number of microorganisms and extract necrotic tissue, and finally to obturate this system and thus prevent recontamination (Del Fabbro et al., 2007). However, it is agreed that one of the most frequent causes of failure in endodontic therapy is the inability to recognize and adequately treat the entire canal system (Karaman et al., 2011; Verma \& Love, 2011; Vertucci, 2005; Zheng et al., 2010). In order to achieve treatment success, perfect knowledge of dental morphology is relevant, particularly of the internal anatomy (Cleghorn et al., 2006).

Root anatomy complexity is undermined in available literature, and its emphasized that the clinician should understand its possible variations (al Shalabi et al., 2000; Prabhakar et al., 2013; Abarca et al., 2014; Jiménez et al., 2015; Vaillard Jiménez et al., 2015). The canal system of the maxillary first and second molar is complex and difficult to study. It is reported that the mesiobuccal (MB) root presents the greatest variation and many studies have stressed the need to be aware of the presence of extra canals in this root (al Shalabi et al.).

The presence of a second canal in the MB root (MB2) is reported to be between $18 \%$ and $95 \%$ (Bauman et al., 2011). This wide range is due to the designs and methods used in these studies (Peeters, Suardita, \& Setijanto, 2011) and could also be associated with ethnic differences, gender and age of the study populations (Cleghorn et al.).

\footnotetext{
* Master of Dentistry program, Faculty of Dentistry, Universidad de la Frontera, Temuco, Chile.

** Faculty of Dentistry, Universidad San Sebastián, Puerto Montt, Chile.

*** Begmax Radiology Center, Santiago, Chile.

**** Department of Pediatric Dentistry and Orthodontic, Faculty of Dentistry, Universidad de la Frontera, Temuco, Chile.

****** CIEESPO, Faculty of Dentistry, Universidad de la Frontera, Temuco, Chile.

******* Faculty of Dentistry, Universidad San Sebastián, Santiago, Chile.

******** Department of Public Health, Faculty of Medicine, Universidad de la Frontera, Temuco, Chile

******** Center of Research in Biomedical Science, Universidad Autónoma de Chile, Temuco, Chile.
} 
The aim of this study was to determine the morphology of the mesial root canal system of maxillary molars and the frequency of the MB2 canal in the mesial root of first and second molars in the different root thirds and its relation with patient's age and sex.

\section{MATERIAL AND METHOD}

This study was conducted following approval from the Scientific Ethics Committee of the University of La Frontera, in accordance with the ethical standards set forth in the Declaration of Helsinki. Cone-beam computed tomography (CBCT) scans of the maxilla of 1280 Chilean patients, taken as part of the diagnosis or planning of dental treatments, between January 2010 and June 2013 in the Begmax Center in Santiago, Chile, were examined. The CBCT scans that were included presented first or second molars in patients between 8 and 77 years olds. Those who had teeth with endodontic treatment, open apex, signs of apical resorption, apical surgery, or extensive metallic restorations that prevented correct observation were excluded.

CBCT scans were obtained with a Gendex CB500 imaging system that uses $120 \mathrm{kVp}$ and $5 \mathrm{~mA}$. The voxel size was $0.2 \mathrm{~mm}$ and the thickness of the cut was $0.2 \mathrm{~mm}$. Every scan was taken by dental radiologists following the manufacturer's instructions. Prior to the evaluation of the scans, two observers underwent theoretical training to agree on protocol and observation criteria. Then, 20 teeth scans were evaluated independently by each observer under the same conditions of time of day, light and screen resolution. Ten days later the procedure was repeated under the same conditions. With the collected data the intraobserver and interobserver agreement was calculated using Cohen's Kappa index, and a very good agreement was obtained (kappa= 0.81) (Cerda \& Villarroel, 2008).

The scans were analysed using the iCATVision software v 1.8.1.10 in a darkroom on 21" LCD monitors with a resolution of $1280 \times 1024$ pixels. The root was divided in equal thirds (Fig. 1), and each third was checked for the presence of the MB2 canal. It was considered present when it was found in at least one root third.

Vertucci's classification was used to determine the morphology of the mesial root canal system of the maxillary first and second molars.

Data were processed with the Stata software v.11.0. A descriptive analysis was conducted to establish the distribution of the study variables. Pearson's chi-squared test was used to compare the percentages. Cuzick's test for trend was used for the trend analysis. The level of significance was $5 \%$.

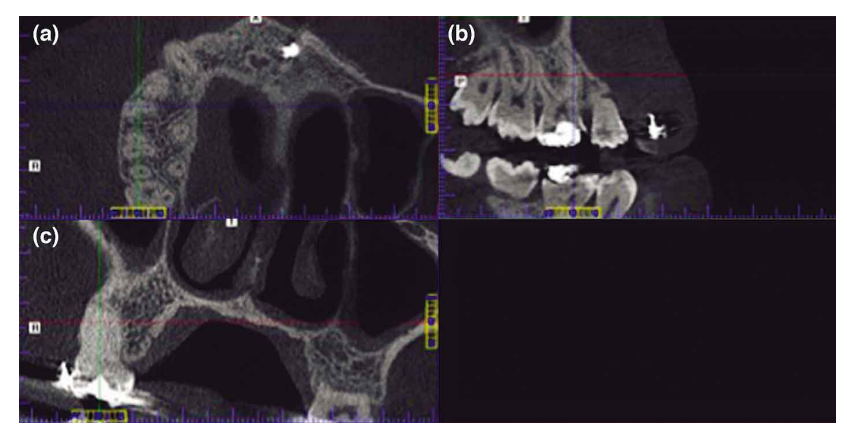

Fig. 1. Measurement system used to determine the presence of the second mesiobuccal canal. (a) Coronal cut used to determine in each root third the presence of the MB2 canal. (b) Sagittal cut used to locate the most apical and most coronal point of the root and to divide it in equidistant thirds; it was also used to leave the canal as vertical as possible. (c) Axial cut used to corroborate the type of canal and that this was as vertical as possible.

\section{RESULTS}

Of the 1280 CBCT scans examined, 508 fulfilled the selection criteria. Fifty nine point three percent of the CBCT scans included were of women and the average age was $33.3 \pm 15.6$, ranging from 8 to 77 years olds.

The total number of teeth observed was 1374 , of which 802 were maxillary first molars, 406 rights and 396 left. Five hundred seventy two maxillary second molars were included: 283 right and 289 left.

The frequency of the MB2 canal in maxillary first molars (1MS) was $73.44 \%$ and in second molars (2MS) $42.48 \%$. Table I shows the frequency of the MB2 canal by root third and side.

The presence of the MB2 canal in all root thirds was $32.5 \%$ in the right first molars (1MSR) and $16.6 \%$ in the right second molars (2MSR). In the left first molars (1MSL) $34.3 \%$ of the canals separated at the apical third and $12.8 \%$ of the left second molars (2MSL) had MB2 in all thirds. Figure 2 illustrates the presence of the MB2 canal in maxillary first and second molars.

No statistically significant association was found for the presence of the MB2 canal according to side in maxillary first and second molars (Table II). Nor was any statistically significant association found in the frequency of the MB2 canal according to gender (Table III). 
However, when presence of MB2 was associated with age range, a statistically significant association was found. As the age increased, so did the presence of the MB2 canal in the maxillary first and second molars $(\mathrm{P}<0.001$ and $\mathrm{P}=0.023$, respectively) (Table IV). The morphology of the mesial root canal system of maxillary first and second molars is shown in Table $\mathrm{V}$.

Table I. Distribution of MB2 canal according to root third.

\begin{tabular}{lcccc}
\hline Tooth & $\mathbf{n}$ & $\begin{array}{c}\text { Cervical } \\
\mathbf{( \% )}\end{array}$ & $\begin{array}{c}\text { Middle } \\
\mathbf{( \% )}\end{array}$ & $\begin{array}{c}\text { Apical } \\
\mathbf{( \% )}\end{array}$ \\
\hline 1MSR & 406 & 71.43 & 56.90 & 37.93 \\
1 MSL & 396 & 69.44 & 54.55 & 37.63 \\
2MSR & 283 & 39.93 & 32.16 & 19.43 \\
2MSL & 289 & 36.33 & 29.76 & 16.96 \\
\hline
\end{tabular}

1MSR= Right first molar, 1MSL= Left first molar, 2MSR= Right second molar, $2 \mathrm{MSL}=$ Left second molar.

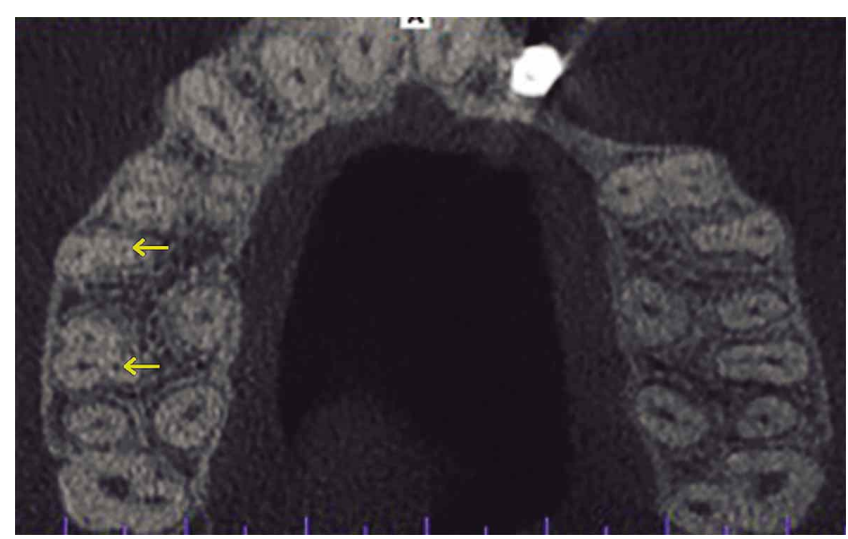

Fig. 2. Presence of the MB2 canal in maxillary first and second molar.

Table II. Prevalence of MB2 canal in first and second molars according to side.

\begin{tabular}{|c|c|c|c|c|c|}
\hline \multicolumn{2}{|c|}{ Maxillary $1 \mathrm{~s}^{\mathrm{t}}$ Molar } & \multirow[b]{2}{*}{$\mathbf{p}$} & \multicolumn{2}{|c|}{ Maxillary $2^{\text {nd }}$ Molar } & \multirow[b]{2}{*}{$\mathbf{p}$} \\
\hline Prevalence MB2 & $\mathbf{n}$ & & Prevalence MB2 & $\mathbf{n}$ & \\
\hline$(9 / d) 2$ & 406 & 0.275 & $4(3 \%$ d)1 & 122 & 0.764 \\
\hline 71.72 & 396 & & 41.87 & 289 & \\
\hline 73.44 & 802 & & 42.48 & 572 & \\
\hline
\end{tabular}

Table III. Presence of MB2 canal according to sex.

\begin{tabular}{|c|c|c|c|c|c|c|}
\hline \multirow[b]{2}{*}{ Sex } & \multicolumn{2}{|c|}{ Maxillary $1^{\text {st }}$ Molar } & \multirow[b]{2}{*}{$\mathbf{p}$} & \multicolumn{2}{|c|}{ Maxillary $2^{\text {nd }}$ Molar } & \multirow[b]{2}{*}{$\mathbf{p}$} \\
\hline & Prevalence MB2 & $\mathbf{n}$ & & Prevalence MB2 & $\mathbf{n}$ & \\
\hline Female & $7(\rho / 2) 8$ & 477 & 0.093 & $3(8.0) 8$ & 313 & 0.062 \\
\hline Male & 76.62 & 325 & & 46.72 & 259 & \\
\hline Total & 73.44 & 802 & & 42.48 & 572 & \\
\hline
\end{tabular}

Table IV. Frequency of MB2 by age range.

\begin{tabular}{lccccccc}
\hline & \multicolumn{2}{c}{ Maxillary $\mathbf{1}^{\text {st }}$ Molar } & & \multicolumn{3}{c}{ Maxillary 2nd Molar } & \\
\cline { 2 - 3 } Age (y) & Prevalence $\mathbf{M B 2}$ & $\mathbf{n}$ & $\mathbf{p}$ & Prevalence MB2 & $\mathbf{n}$ & p \\
\hline 8 to 18 & 55.75 & 226 & & $0.001^{*}$ & 28.30 & 53 & \multirow{2}{*}{$0.023^{*}$} \\
19 to 44 & 79.65 & 403 & & 42.48 & 379 & \\
$\geq 45$ & 82.08 & 173 & & & 47.86 & 140 & \\
Total & 73.44 & 802 & & & 42.48 & 572 & \\
\hline
\end{tabular}

* $\mathrm{P}<0.05$, statistically significant. Cuzick's test for trend.

Table V. Morphology distribution of the mesial root canal system of maxillary first and second molars according to Vertucci's Method.

\begin{tabular}{lcccccccc}
\hline \multirow{2}{*}{$\begin{array}{l}\text { Canal } \\
\text { Types }\end{array}$} & \multicolumn{2}{c}{ 1MSR } & \multicolumn{2}{c}{ 1MSL } & \multicolumn{2}{c}{ 2MSR } & \multicolumn{2}{c}{ 2MSL } \\
\cline { 2 - 9 } & $\mathbf{n}$ & $\mathbf{\%}$ & $\mathbf{n}$ & $\mathbf{\%}$ & $\mathbf{n}$ & $\mathbf{\%}$ & $\mathbf{n}$ & \% \\
\hline I & 101 & 24.88 & 112 & 28.28 & 161 & 56.89 & 168 & 58.13 \\
II & 147 & 36.2 & 133 & 33.59 & 64 & 22.61 & 68 & 23.53 \\
III & 4 & 0.99 & 2 & 0.51 & 3 & 1.06 & 4 & 1.38 \\
IV & 132 & 32.51 & 136 & 34.34 & 47 & 16.61 & 37 & 12.8 \\
V & 11 & 2.71 & 7 & 1.77 & 6 & 2.12 & 12 & 4.17 \\
VI & 11 & 2.71 & 6 & 1.52 & 2 & 0.71 & 0 & $0 \%$ \\
\hline
\end{tabular}

$1 \mathrm{MSR}=$ Right first molar, $1 \mathrm{MSL}=$ Left first molar, $2 \mathrm{MSR}=$ Right second molar, $2 \mathrm{MSL}=$ Left second molar. 


\section{DISCUSSION}

Knowing the frequency of the MB2 canal in maxillary first and second molars and its relation with a patient's gender and age is relevant to the success of endodontic treatment. Many techniques have been used to study the morphology of the root canal system, including staining and bleaching, conventional and digital x-rays, and most recently CBCT (Neelakantan et al., 2010; Betancourt et al., 2015). In this work $\mathrm{CBCT}$ was used to determine the frequency of the MB2 canal because it is a non-invasive method with an effectiveness similar to bleaching and staining (Neelakantan et al.). It is currently considered the gold standard for these types of studies. Moreover, CBCT guarantees the ability to evaluate age, gender and side of the tooth (Zheng et al.).

The results in this study revealed a frequency of $74.44 \%$ in maxillary first molars and $42.48 \%$ in second molars, results very similar to those of Lee et al. (2011), who found a frequency of $70.5 \%$ in first molars and $41.6 \%$ in second molars, and the results of al Shalabi et al., who obtained $78 \%$ and $58 \%$ frequency of the MB2 canal in the first and second molars, respectively. This is in contrast to the results obtained by Silva et al. (2014), with frequencies of $42.65 \%$ for the maxillary first molar and $34.32 \%$ for the second molar, and those obtained by Reis et al. (2013), with $91 \%$ and $79.3 \%$ for the first and second molar, respectively. These differences in frequency reveal the anatomical variability of the mesial root in maxillary molars, which could be explained by the sample size, the observation technique (Peeters et al., 2011) and the patients' ethnicity (Cleghorn et al.; Zhang et al., 2011).

In this study, as was observed in the work by Reis $e t$ $a l$. , the frequency in the MB2 canal decreased towards the root apex (Reis et al.).

When the presence of the MB2 canal and the patient's age was assessed, we observed a tendency to increase with age, which is different from what was observed by other authors (Reis et al.; Lee et al.), who found that the presence of the MB2 canal decreased with age. This may be because in our study the sample of patients over 55 years of age represented only $5 \%$ of all the teeth included.

It should be mentioned that the visualization of two canals in the MB root is complex in young patients, because in the formation of the MB2 canal, the septum that separates the two canals is of secondary dentin, which means it works itself into position as the person ages. Therefore, in many cases, they are categorised as one "ribbon shaped" canal and not as two canals.
When the relationship between gender and tooth side was assessed, no significant differences were found, which is consistent with what has been published in current literature (Lee et al.; Reis et al.; Zhang et al.).

In relation to morphology it was found that type II and IV of Vertucci's Method were the most prevalent when the MB2 canal was present, just as was reported by $\mathrm{Ng}$ et al. (2001) and by Kim et al. (2012).

\section{CONCLUSION}

In this study, it was determined that more than $30 \%$ of first molars had MB2 canals present in all root thirds and that more than $13 \%$ of the maxillary second molars also exhibited this characteristic. Overall, $70 \%$ of maxillary first molars and over $40 \%$ of maxillary second molars show MB2 canals, results that are of clinical relevance. This could explain the high rate of treatment failure in these teeth and might encourage the clinician to pay more attention to the localization and treatment of this canal in order to improve the prognosis.

Given the anatomical complexity of the mesiobuccal root and the high frequency of the MB2 canal, the clinician must assume the existence of two canals in this root, and CBCT scanning is a good way to initially identify the MB2 canal in the different root thirds.

\section{ACKNOWLEDGEMENTS}

Jaime Abarca is a student in the Master of Dentistry Program in the Dentistry Faculty of the Universidad de La Frontera, Temuco, Chile.

ABARCA, J.; GÓMEZ, B.; ZAROR C.; MONARDES, H.; BUSTOS, L. \& CANTIN, M. Determinación de la morfología de la raíz mesial y la frecuencia del canal MB2 en molares maxilares usando Tomografía Computadorizada de Haz Cónico. Int. J. Morphol., 33(4):1333-1337, 2015.

RESUMEN: Determinar la morfología del sistema de canales de la raíz mesial de molares maxilares y la frecuencia del canal MB2 usando tomografía computadorizada de haz cónico (TCHC). Un total de 1374 dientes, primeros molares maxilares ( $1 \mathrm{MS}, \mathrm{n}=802$ ) y segundos molares maxilares (2MS, $n=572$ ) de 508 pacientes Chi- 
lenos entre 8 y 77 años fueron evaluados a través de la TCHC. Se evaluó la raíz mesiobucal en todos sus tercio. La clasificación de Vertucci fue utilizada para determinar la morfología del sistema de canales. Los datos fueron analizados con los test Chi-Cuadrado de Pearson y la prueba de tendencia de Cuzick. La frecuencia del canal MB2 para el 1MS fue 73,44\% y el 2MS 42,48\%. La morfología mas frecuente en el 1MS y 2MS fueron el tipo II y I de Vertucci, respectivamente. No se encontró asociación significativa entre la frecuencia y el lado o sexo ( $p>0,005)$. Una asociación positive fue encontrada a medida que aumentaba la edad en ambos $1 \mathrm{MS}$ y $2 \mathrm{MS}$ ( $\mathrm{p}<0,001$ y $\mathrm{p}=0,023$, respectivamente). Dada la complejidad de la anatomía de la raíz mesiobucal y la frecuente presencia del canal MB2, el clínico debe asumir la existencia de dos canales en esta raíz. La TCHC es una buena manera de identificar tempranamente el canal en los diferentes tercio radiculares.

PALABRAS CLAVE: CBCT; Canal mesiobucal secundario; MB2; Molares maxilares; Sistema de canales radiculares.

\section{REFERENCES}

Abarca, J.; Zaror, C.; Monardes, H.; Hermosilla, V.; Muñoz, C. \& Cantin, M. Morphology of the physiological apical foramen in maxillary and mandibular first molars. Int. J. Morphol., 32(2):671-7, 2014.

al Shalabi, R. M.; Omer, O. E.; Glennon, J.; Jennings, M. \& Claffey, N. M. Root canal anatomy of maxillary first and second permanent molars. Int. Endod. J., 33(5):405-14, 2000.

Bauman, R.; Scarfe, W.; Clark, S.; Morelli, J.; Scheetz, J. \& Farman, A. Ex vivo detection of mesiobuccal canals in maxillary molars using CBCT at four different isotropic voxel dimensions. Int. Endod. J., 44(8):7528, 2011.

Betancourt, P.; Navarro, P.; Cantín, M. \& Fuentes, R. Cone-beam computed tomography study of prevalence and location of MB2 canal in the mesiobuccal root of the maxillary second molar. Int. J. Clin. Exp. Med., 8(6):9128-34, 2015.

Cerda L., J. \& Villarroel del P., L. Evaluación de la concordancia interobservador en investigación pediátrica: Coeficiente de Kappa. Rev. Chil. Pediatr., 79(1):54-8., 2008.

Cleghorn, B. M.; Christie, W. H. \& Dong, C. C. Root and root canal morphology of the human permanent maxillary first molar: a literature review. J. Endod., 32(9):813-21, 2006.

Del Fabbro, M,; Taschieri, S.; Testori, T.; Francetti, L. \& Weinstein, R. L. Surgical versus non-surgical endodontic re-treatment for periradicular lesions. Cochrane Database Syst. Rev., (3):CD005511, 2007.

Karaman, G. T.; Onay, E. O.; Ungor, M. \& Colak, M. Evaluating the potential key factors in assessing the morphology of mesiobuccal canal in maxillary first and second molars. Aust. Endod. J., 37(3):13440, 2011.

Kim, Y.; Lee, S. J. \& Woo, J. Morphology of maxillary first and second molars analyzed by cone-beam computed tomography in a korean population: variations in the number of roots and canals and the incidence of fusion. J. Endod., 38(8):1063-8, 2012.
Lee, J. H.; Kim, K. D.; Lee, J. K.; Park, W.; Jeong, J. S.; Lee, Y.; Gu, Y.; Chang, S. W.; Son, W. J.; Lee, W. C.; Baek, S. H.; Bae, K. S. \& Kum, K. Y. Mesiobuccal root canal anatomy of Korean maxillary first and second molars by cone-beam computed tomography. Oral Surg. Oral Med. Oral Pathol. Oral Radiol. Endod., 111(6):785-91, 2011.

Neelakantan, P.; Subbarao, C. \& Subbarao, C. V. Comparative evaluation of modified canal staining and clearing technique, cone-beam computed tomography, peripheral quantitative computed tomography, spiral computed tomography, and plain and contrast medium-enhanced digital radiography in studying root canal morphology. J. Endod., 36(9):1547$51,2010$.

Ng, Y. L.; Aung, T. H.; Alavi, A. \& Gulabivala, K. Root and canal morphology of Burmese maxillary molars. Int. Endod. J., 34(8):620-30, 2001.

Peeters, H. H.; Suardita, K. \& Setijanto, D. Prevalence of a second canal in the mesiobuccal root of permanent maxillary first molars from an Indonesian population. J. Oral Sci., 53(4):489-94, 2011.

Prabhakar, J.; Priya, M. S.; Doss, L. J. T. \& Sukumaran, V. G. Piecewise straight line approximation of curve existing in slightly curved mesiobuccal root canal of mandibular first molar. A radiographic investigation. Int. J. Morphol., 31(1):131-5, 2013.

Reis, A. G.; Grazziotin-Soares, R.; Barletta, F. B.; Fontanella, V. R. \& Mahl, C. R. Second canal in mesiobuccal root of maxillary molars is correlated with root third and patient age: a cone-beam computed tomographic study. J. Endod., 39(5):588-92, 2013.

Silva, E. J.; Nejaim, Y.; Silva, A. I.; Haiter-Neto, F.; Zaia, A. A. \& Cohenca, N. Evaluation of root canal configuration of maxillary molars in a Brazilian population using cone-beam computed tomographic imaging: an in vivo study. J. Endod., 40(2):173-6, 2014.

Vaillard Jiménez, E.; Hitzil Muñoz, E.; Castillo Domínguez, L. Characteristics of roots canals of deciduous teeth. Int. J. Odontostomat., 9(1):159-64, 2015.

Verma, P. \& Love, R. M. A Micro CT study of the mesiobuccal root canal morphology of the maxillary first molar tooth. Int. Endod. J., 44(3):2107, 2011.

Vertucci, F. J. Root canal morphology and its relationship to endodontic procedures. Endod. Top., 10(1):3-29, 2005.

Zhang, R.; Yang, H.; Yu, X.; Wang, H.; Hu, T. \& Dummer, P. M. Use of CBCT to identify the morphology of maxillary permanent molar teeth in a Chinese subpopulation. Int. Endod. J., 44(2):162-9, 2011.

Zheng, Q. H.; Wang, Y.; Zhou, X. D.; Wang, Q.; Zheng, G. N. \& Huang, D. M. A cone-beam computed tomography study of maxillary first permanent molar root and canal morphology in a Chinese population. $J$. Endod., 36(9):1480-4, 2010.

Correspondence to:

Jaime Abarca

Faculty of Dentistry

Universidad San Sebastián

Lago Panguipulli 1390

Pelluco Alto

Puerto Montt - CHILE

Received: 07-06-2015

Accepted: 24-09-2015

Email: jabarcar@docenteuss.cl 